\title{
Frontières
}

\section{Marc Chabot, En finir avec soi, Montréal, VLB, 1997, 161 pages}

\section{Éric Volant}

Volume 12, numéro 1, automne 1999

URI : https://id.erudit.org/iderudit/1074522ar

DOI : https://doi.org/10.7202/1074522ar

Aller au sommaire du numéro

Éditeur(s)

Université du Québec à Montréal

ISSN

1180-3479 (imprimé)

1916-0976 (numérique)

Découvrir la revue

Citer ce compte rendu

Volant, É. (1999). Compte rendu de [Marc Chabot, En finir avec soi, Montréal,

VLB, 1997, 161 pages]. Frontières, 12(1), 115-116.

https://doi.org/10.7202/1074522ar

Ce document est protégé par la loi sur le droit d'auteur. L'utilisation des services d'Érudit (y compris la reproduction) est assujettie à sa politique d'utilisation que vous pouvez consulter en ligne.

https://apropos.erudit.org/fr/usagers/politique-dutilisation/
Cet article est diffusé et préservé par Érudit.

Érudit est un consortium interuniversitaire sans but lucratif composé de l'Université de Montréal, l'Université Laval et l'Université du Québec à Montréal. Il a pour mission la promotion et la valorisation de la recherche. https://www.erudit.org/fr/ 
Marc Chabot

\section{En finir avec soi}

Montréal, VLB, 1997, 161 pages.

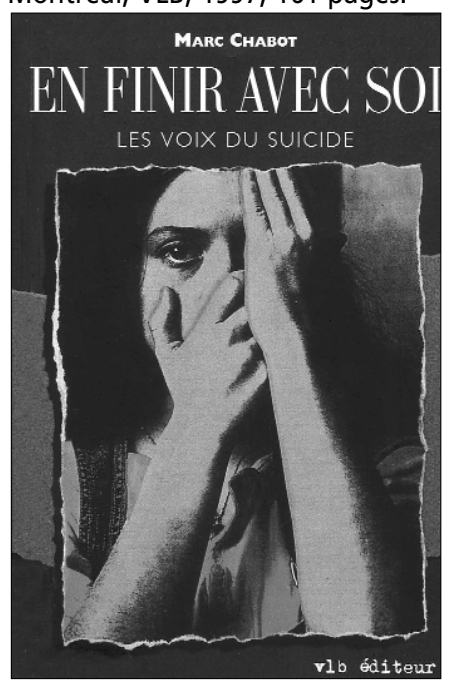

Dès l'avant-propos, l'auteur révèle ses couleurs. Loin de lui la prétention de vouloir résoudre le problème du suicide. Son projet est plutôt «de marcher quelques heures avec ceux et celles qui ont choisi de se taire définitivement" (p. 15). II veut écouter les voix des suicidés, illustres ou inconnus du public, il veut entendre parler leur silence. Mais ce silence est chargé de discours, car le suicidé "parle de sa vie, de sa société, de sa famille, de ses proches, de sa philosophie, de sa souffrance, de son malheur, de son incapacité d'être» (p. 26).

Approche littéraire: à travers les différents chapitres, on entend résonner ou murmurer les voix de Romain Gary, Virginia Woolf, Sylvia
Plath. Mais un chapitre entier est consacré à Stig Dagerman, Cesare Pavese et Hubert Aquin. Les personnages fictifs de Ben et Sera dans le roman et film Leaving Las Vegas de John O'Brien et de Mademoiselle Else d'Arthur Schnitzler ont eux aussi droit chacun à un chapitre. Tous ces personnages historiques ou romanesques se livrent librement dans ces pages. L'auteur recueille leurs paroles comme autant de confidences et les agrémente de ses réflexions personnelles. Le lecteur y trouvera une floraison de citations fertiles en images et en pensées.

Approche philosophique: les chapitres plus philosophiques sont de facture fragmentaire. L'écriture brisée donne au texte une cadence rythmée et les nombreux aphorismes atteignent, à certains moments, une densité de pensée susceptible de saisir l'esprit du lecteur. Lorsque l'auteur affirme que "nous sommes tous des suicidés», il essaie de nous convaincre que «nous passons une bonne partie de notre vie à tuer ce que nous sommes et ce que nous voulons être» (p. 18). Le chapitre IV, intitulé Philosophie et suicide a une tournure nettement éthique. L'auteur s'interroge sur le bien-fondé du droit à une mort douce, mais aussi sur le «bien vivre» qui n'est synonyme ni du uvivre le plus longtemps possible» ni du "vivre vite». Le «bien vivre» évoque la satisfaction que l'on éprouve dans son être et dans sa relation avec autrui. Lorsque le «mal vivre» s'installe de façon durable, le suicidaire choisit de mourir maintenant. Tout le problème est de définir ce "maintenant», de trouver les bons critères d'une mort dite opportune. Le chapitre $X$ pose les jalons d'une métaphysique du suicide. Au-dessus de ces pages plane l'esprit de Schopenhauer qui a écrit: "L'histoire d'une vie est toujours I'histoire d'une souffrance» (p. 144) À cette problématique existentielle, Chabot propose la solution apportée par le philosophe allemand: l'art et ses œuvres. L'art, qui est autre chose que le divertissement, donne à l'homme l'opportunité de choisir d'être humain et de le devenir. En 
rapport avec ce projet de vie esthétique, le lecteur ne peut oublier l'affirmation, étonnamment universelle, de l'auteur dans le chapitre I: "Le suicidaire est avide de ce beau. C'est un absolu dont il fait son pain. Je crois que le suicidaire est même prêt à sacrifier le sens au profit du beau» (p. 31). Nous admettons que le beau peut être chez certains suicidaires un prétexte soit pour vivre, soit pour mourir et que la sensibilité peut l'emporter sur la raison. Mais peut-on généraliser ce souci du beau pour en faire le pain quotidien de tous les suicidaires?

Dans son dernier chapitre, l'auteur craint que «nous allons vers plus de suicides" (p. 158) à cause de la fragilité et du vide du langage contemporain, de son caractère utilitaire. Entre le langage brut de la violence et le beau parler élitiste, il n'y a plus de place pour le langage du cœur. Le suicide est "le cri d'un être parlant qui ne sait pas dire et qui ne peut pas dire» (p. 153) et qui n'arrive pas à faire entendre sa voix. L'auteur espère que son livre soit "un commencement». Un commencement de quoi? D'une meilleure écoute de la voix du cœur, capable de dire son mal?

Éric Volant 